\title{
Entre a Arbitragem Brasileira e a Arbitragem Europeia: Um estudo acerca da Agência Nacional de Telecomunicações (ANATEL) e a Office of Comunications (OFCOM)
}

Between the Brazilian and European Arbitration: A study of the National Telecommunications Agency (ANATEL) and the Office of Communications (OFCOM)

\section{José Albenes Bezerra Júnior*}

\section{Resumo}

Propósito - A procura pela arbitragem como meio de resolução de litígios se mostra importante em função do grande volume de causas submetidas ao julgamento do Estadojuiz, em número inversamente proporcional ao preparo técnico daqueles que são investidos na função jurisdicional por ato estatal. Atualmente, falar em composição extrajudicial de conflitos no campo da regulação significa adentrar em um cenário de grandes discussões e debates. Dessa forma, o texto busca construir razões para a resolução de litígios no âmbito das telecomunicações por meio da arbitragem, inclusive, face a experiência europeia, a exemplo da OFCOM.

Metodologia/Abordagem/Design - Inicialmente será feita uma análise histórica acerca da arbitragem. Num momento posterior, discutir-se-á o fenômeno da regulação e a vinculação com o campo da arbitragem. Logo depois, será feita uma análise das experiências brasileira e europeia. Por fim, dados serão levantados para evidenciar os motivos que levam a diferenciar o modelo brasileiro do europeu.

Resultados - Uma das atribuições das agências reguladoras é, justamente, a solução de conflitos entre os agentes do setor, algo que na Agência Nacional de Telecomunicações (ANATEL), é realizado em sua maioria apenas em nível administrativo. Quando se analisam as formas de resolução de disputas na Comunidade Europeia, observa-se uma realidade peculiar. Em grandes disputas que ocorrem no continente, é mais comum utilizar-se a arbitragem do que o próprio Poder Judiciário. Em verdade, a arbitragem pode ser utilizada pela ANATEL como uma ferramenta importante na garantia de uma ampla, livre e justa concorrência entre as prestadoras de serviços de telecomunicações, na medida em que coíbe a morosidade do Poder Judiciário e a possibilidade de discussões meramente protelatórias, viabilizando a prolação célere de uma decisão que, muitas vezes, afetará a esfera jurídica de praticamente todos os usuários dos serviços de telecomunicações. Confere-se, assim, um grande prestígio a esses métodos de resolução de disputas, na medida em que eles propiciam uma neutralidade de foro. Não se confere a decisão ao Poder Judiciário ou ao órgão regulador de um país específico, mas escolhemse árbitros a partir do comum acordo das partes ou, ainda, apontam-se instituições de âmbito internacional que prestam o serviço de arbitragem em disputas comerciais.

*Graduado em Direito pela Universidade de Fortaleza. Mestre em Direito pela Universidade Federal do Rio Grande do Norte. Professor da Universidade Federal Rural do Semiárido. E-mail: albenes.junior@ufersa.edu.br.

BEZERRA JÚNIOR, J. A. Entre a Arbitragem Brasileira e a Arbitragem Europeia: Um estudo acerca da Agência Nacional de Telecomunicaçós (ANATEL) e a Office of Comunications (OFCOM). Revista de Direito, Estado e Telecomunicações, Brasília, v. 9, n. 1, p. 69-92, maio de 2017. 
Palavras-chave: ANATEL, OFCOM, arbitragem, resolução de disputas, comparação.

\section{Abstract}

Purpose: The demand for arbitration as a dispute resolution is important due to the large volume of cases to be adjudicated at the Judiciary system and its lack of technical expertise to do so. The topic of alternative dispute resolution is clouded with debates of how far should it go before interfering in the core functions of the Judiciary. Thus, this paper seeks to support the use of arbitration in the Brazilian telecommunications sector, inspired by the experience of OFCOM.

Methodology/Approach/Design: The paper starts with a historical analysis on the institute of the arbitrage followed by its connection with the regulatory phenomenon in Brazil and Europe. The study format follows a comparative approach by identifying the main characteristics of arbitration in both Brazilian and European telecommunications models.

Results: One of the duties of the regulatory agencies is precisely the solution of conflicts between players in the sector at the administrative level. When analyzing the forms of dispute resolution in the European Union, a peculiar behavior can be highlighted. In major disputes that occur on the continent, it is more common to use arbitration than the judiciary. In fact, arbitration can be used by ANATEL as an important tool to ensure a broad, free and fair competition between providers of telecommunications services, as it dodges the slowness of the judiciary and the possibility of sham litigations, enabling the rapid adoption of a decision that often affects the rights of a great number of users of telecommunications services. The high prestige enjoyed by these methods of dispute resolution pays homage to their characteristic of being a neutral forum positioned far from a regulatory agency of a specific country and close to referees chosen by common agreement, or even connected to international institutions that provide the arbitration services in commercial disputes.

Keywords: ANATEL, OFCOM, arbitrage, dispute resolution, comparison.

\section{Introdução}

$\mathrm{O}$ artigo aborda, incialmente, a arbitragem como meio consensual de solução de conflitos que, cada vez mais, ganha força. Traz, também, uma crítica aos métodos de administração da justiça brasileira, fundamentados na morosidade e na complexidade do sistema. Seu custo, bem como sua facilidade para o ingresso, torna seu acesso indistinto a todos o que não necessariamente significa uma adequada prestação jurisdicional, muito menos a concretização satisfatória dos valores constitucionais.

Ainda no início do texto, observar-se-á que a função jurisdicional do órgão regulador brasileiro é ainda pouco debatida, em parte pelo fato de a Lei Geral de Telecomunicações não ter aberto possibilidades novas e significativas para a atuação da Administração Pública nesse sentido. Dessa forma, o artigo analisará os órgãos reguladores brasileiro e o europeu que exercem a função de 
dirimir conflitos entre operadoras de telecomunicações e, particularmente, como é usada a arbitragem para isso. Partindo dessa premissa, analisam-se criticamente os meios que a ANATEL e a OFCOM possuem para atuar na resolução dessas disputas, formulando-se questões para que esse papel do órgão regulador nacional possa ser aprimorado, face o órgão regulador europeu.

Em momento, posterior, tratar-se-á do fenômeno do Estado Regulador, levando em consideração a manifestação da atuação reguladora como uma atuação de poder político, caracterizando-a como um projeto de direito público.

$\mathrm{O}$ texto gravita em torno das agências reguladoras, quais sejam, a brasileira Agência Nacional de Telecomunicações (ANATEL) e a europeia Office off Comunication (OFCOM), detalhando os instrumentos jurídicos de sua criação, especificidades e natureza jurídica das mesmas. Por fim, o texto versa sobre litígios envolvendo agentes do setor regulado ou um deles e a agência reguladora.

Para isso, constata-se que a possibilidade de utilização dos meios consensuais de resolução de disputas consubstancia a adoção de uma ferramenta de superação dessa crise, reforçando a coerência do sistema. A atuação estatal no sentido de possibilitar os meios alternativos de resolução de controvérsias, entre eles a arbitragem, traduz-se em uma atuação regulatória do Estado.

\section{Introdução à Arbitragem}

O recurso à arbitragem como meio de solução de resolução de conflitos possui uma longa história. A arbitragem é um dos mais antigos meios de composição de conflitos pela heterocomposição, ou seja, a solução do conflito por um terceiro imparcial. Segundo DOLINGER (2005, p.23), a arbitragem já estava presente entre os hebreus na antiguidade, descrito no pentateuco (DOLINGER, 2005, p.24) que relata conflitos decididos por árbitro, a exemplo de Jacó e Labão.

A arbitragem remonta, também, à antiguidade grega, onde serviu para resolver conflitos entre cidades que estavam frequentemente em guerra. No Direito Romano, a arbitragem voluntária e facultativa era admitida e até estimulada; sempre foi aceita e até mesmo incentivada. A arbitragem obrigatória também existiu entre as fases das ações da lei - legis actiones - e do processo formulário - legis formulas (CARREAU, BICHARA, 2015, p. 673). Foi praticada também na Idade Média, quando o árbitro "supremo" era o papa, em razão da autoridade espiritual e moral (MELLO, 2004, p.1442).

Todavia, com o nascimento do Estado Moderno, a arbitragem passou a perder sua importância. Um renascimento brusco da arbitragem ocorreu com o Tratado de Amizade, de Comércio e Navegação, de 09 de novembro de 1794, celebrado entre os Estados Unidos e a Grã-Bretanha, conhecido como Tratado Nacional de Telecomunicaçoes (ANATEL) e a Office of Comunications (OFCOM). Revista de Direito, Estado e Telecomunicações, Brasília, v. 9, n. 1, p. 69-92, maio de 2017. 
Jay, que instituiu o recurso sistemático à arbitragem para resolver os conflitos decorrentes da independência americana, como, por exemplo, a fixação da fronteira com o Canadá, ou a avaliação de todas as sequelas financeiras das hostilidades militares (CARREAU, BICHARA, 2015, p. 674). Observa-se, assim, que a arbitragem passou a ganhar espaço, inclusive, em âmbito internacional.

A arbitragem passou a tomar contornos de um meio que, ao lado da jurisdição estatal, representa uma forma heterocompositiva de solução de conflitos. As partes capazes, de comum acordo, diante de um litígio, ou por meio de cláusula contratual, estabelecem que um terceiro, ou colegiado, terá poderes para solucionar a controvérsia, sem a intervenção estatal, sendo que a decisão terá a mesma eficácia que uma sentença judicial.

$\mathrm{Na}$ busca da melhor alternativa às partes, em sua essência temos na arbitragem o modelo mais adequado para diversas situações, como em conflitos complexos, envolvendo aprofundamento em matérias específicas, e exigindo estrutura e tratamento mais dedicado, difíceis de serem obtidos no Poder Judiciário pelas suas características e colossal volume de trabalho. No que tange às discussões sobre a arbitragem como meio "alternativo" de solução de conflitos, CARMONA (2009, p.31) prefere denominar a arbitragem como "meio adequado" de solução de controvérsias.

Em nosso país, a arbitragem estava prevista no Código Civil de 1916 entre os meios indiretos de pagamento, sob o título de "compromisso" (arts. 1.037 a 1.048), mas não encontrou larga utilização como meio de solução de conflitos, tendo em vista que, nos arts. 1.085 a 1.102, o Código de Processo Civil exigia a homologação do então denominado "laudo arbitral" (hoje equivalente à sentença arbitral), por sentença judicial com todos os recursos inerentes. Com isso, o Poder Judiciário se transformava em "segundo grau de jurisdição" da arbitragem.

A Lei 9.307, de 23 de setembro de 1996, acabou com a necessidade de homologação judicial da sentença arbitral e equiparou o árbitro ao juiz togado no desempenho da arbitragem (art. 18), logo afirmando que o árbitro é juiz de fato e de direito, e a sentença que proferir não fica sujeita a recurso ou a homologação pelo Poder Judiciário. Esclarecendo, dessa forma, que a sua decisão é sentença e, como tal, constitui título executivo judicial (CPC, art. 475$\mathrm{N}$, IV, incluído pela Lei 11.232/2005), fazendo coisa julgada material ao decidir o mérito do conflito.

A arbitragem, dessa forma, passou a resultar de negócio jurídico mediante o qual as partes optam pela solução arbitral, abdicando da jurisdição estatal em razão dos seus direitos patrimoniais e disponíveis. A solução do árbitro é denominada sentença arbitral e sua atividade é indubitavelmente jurisdicional. Como tal, possui a mesma força de uma sentença judicial BEZERRA JÚNIOR, J. A. Entre a Arbitragem Brasileira e a Arbitragem Europeia: Um estudo acerca da Agência Nacional de Telecomunicaçoes (ANATEL) e a Office of Comunications (OFCOM). Revista de Direito, Estado e Telecomunicações, Brasília, v. 9, n. 1, p. 69-92, maio de 2017. 
transitada em julgado, até porque o Código de Processo Civil coloca a decisão arbitral no rol dos títulos executivos judiciais.

É válido acrescentar a informação que o novo código processual civil (2015) adota a dualidade jurisdicional, estabelecendo paralelamente a jurisdição estatal e a jurisdição arbitral, observada nos artigos $3^{\circ}$ e 42 . Observa-se no artigo $3^{\circ}$ que não será excluída da apreciação jurisdicional ameaça ou lesão a direito, bem como será permitida a arbitragem na forma da lei. Já o texto do artigo 42 passa a ideia de que as causas cíveis serão processadas e decidas pelo juiz nos limites de sua competência, ressalvado às partes o direito de instituir juízo arbitral, na forma da lei.

Quanto aos limites impostos à possibilidade de solução arbitral, nos termos do art. $1^{\circ}$ da Lei de Arbitragem (Lei 9.307/1996), a arbitragem se limita à capacidade de contratar e aos direitos patrimoniais e disponíveis. Vejamos: "As pessoas capazes de contratar poderão valer-se da arbitragem para dirimir litígios relativos a direitos patrimoniais disponíveis". Portanto, basta que a pessoa tenha personalidade jurídica para que possa se submeter à arbitragem. Lembre-se que, nos termos do art. $1^{\circ}$ do CC, personalidade jurídica é a capacidade de ser titular de direitos e obrigações, adquirida pela pessoa natural com o nascimento com vida (art. $2^{\circ}$ do CC).

Isto porque estamos no campo da capacidade de gozo dos direitos (capacidade de direito) e não do seu exercício pessoal (capacidade de fato), que depende da inexistência de incapacidades absolutas ou relativas, tal qual delineadas no Código Civil. O que se quer afirmar, diferentemente do que pensam alguns autores, é que as pessoas podem ser representadas ou assistidas na convenção de arbitragem, desde que respeitados os limites decorrentes da matéria, que deve versar sobre direitos patrimoniais disponíveis.

Entre os direitos de cunho patrimonial, encontramos as relações jurídicas de direito obrigacional, ou seja, aquelas que encontram sua origem nos contratos, nos atos ilícitos e nas declarações unilaterais de vontade. Os direitos não patrimoniais, por seu turno, são aqueles ligados aos direitos da personalidade, como o direito à vida, à honra, à imagem, ao nome e ao estado das pessoas, como, por exemplo, a capacidade, a filiação e o poder familiar, entre outros com a mesma natureza.

Todavia, para que possa ser adotada como meio de solução dos conflitos, além de se limitar aos direitos patrimoniais, a arbitragem ainda exige a existência de direitos disponíveis. A disponibilidade dos direitos se liga, conforme pensamos, à possibilidade de alienação e, demais disso e principalmente, àqueles direitos que são passíveis de transação. Assim, por exemplo, não é possível transacionar acerca do direito ao próprio corpo, à liberdade, à igualdade e ao direito à vida. 
Entretanto, esses conceitos não são suficientes para que possamos entender os limites impostos à possibilidade de as partes adotarem a solução arbitral. Nessa medida, a afronta aos direitos indisponíveis, a exemplo dos direitos da personalidade, como é cediço, são indenizáveis e, quanto a essa indenização, cabe a arbitragem, tal qual delineada na Lei 9.307/1996.

Recentemente, a Lei 13.129/2015, veio a reformar a lei de arbitragem, para ampliar o âmbito de aplicação da arbitragem e dispor sobre a escolha dos árbitros quando as partes recorrem a órgão arbitral, a interrupção da prescrição pela instituição da arbitragem, a concessão de tutelas cautelares e de urgência nos casos de arbitragem, a carta arbitral e a sentença arbitral, revogando dispositivos da Lei n ${ }^{\circ}$ 9.307/1996.

\section{Uma Análise Acerca da Regulação}

A regulação, em sua acepção mais fundamental, significa um processo de realimentação contínua da decisão pelos efeitos dessa decisão, reconformando a atitude do regulador em uma cadeia infinita caracterizada pelo planejamento e gerenciamento conjuntural da realidade. Há diversos elementos conceituais da regulação que especificam essa noção fundamental (ARANHA, 2015, p.28).

Um dos elementos é a manifestação da atuação reguladora como uma atuação de poder político, caracterizando-a como um projeto de direito público. Outro elemento é a consciência de que se regula algo que tem suas próprias leis e que, portanto, a regulação potencializa as forças da iniciativa privada em um ambiente parcialmente preexistente e parcialmente criado pela própria atividade reguladora. Por fim, um último elemento é a finalidade da regulação como o alcance de um equilíbrio dinâmico das interações dos atores setoriais em conformidade com um objetivo de interesse geral e não o de mera potencialização de um mercado regulado pretensamente indiferente ao contexto dos direitos políticos e sociais circundantes.

A literatura indicativa e inicial do olhar estatal regulador é ampla. Em seu núcleo de significado, a regulação não exige, nem dispensa a ideia de agências reguladoras e menos ainda a de agências reguladoras independentes. A identidade entre a regulação e tais estruturas estatais das agências reguladoras ocorreu mediante a interdependência construída pela literatura do século XX e início do século XXI entre regulação e Estado regulador, em que foi acoplado à definição de regulação o meio ou veículo de mediação entre o ser político e o setor regulado inaugurado pela prática institucional estadunidense. A íntima relação entre a construção conceitual da regulação e a história institucional do Estado Regulador dos modelos estadunidense e europeu permite falar-se de momentos regulatórios (ARANHA, 2015, p.32). 
O denominado "Estado Regulador" não é uma antítese ou uma negação do Estado de Direito. Ao contrário, o pressupõe, à medida que as medidas de regulação nos mais diversos campos - econômico, social e ambiental - são, antes de tudo, medidas normativas. É evidente que o Estado sempre possuiu - e monopolizou, durante longo período - a regulação, entendendo este fenômeno como a direção das condutas entre indivíduos. O termo ganha, especialmente nas últimas décadas, nova conotação, traduzindo um fenômeno não apenas jurídico, mas socioeconômico de regulação heterônoma de setores específicos utilizando não apenas de meios convencionais (como a sanção negativa, por exemplo) bem como novas alternativas, como o fortalecimento da participação popular, da consensualidade e uma maior preocupação com a indução.

Todavia, este "Estado Regulador", que advém com a derrocada fiscal de um Estado providencialista ainda é fenômeno mais ideológico do que propriamente normativo, ao menos no tocante ao Estado Brasileiro. A Constituição da República Federativa do Brasil de 1988 veio para suplantar um regime ditatorial presente no Brasil desde 1964 até 1988, quando tiveram início os trabalhos constituintes, preocupando-se não apenas em implantar e solidificar a democracia no seio do Estado brasileiro mas, seguindo a tradição de outras constituições, também positivando diversos direitos fundamentais e sociais, os quais exigem, por natureza, ampla atuação estatal para sua implementação (DIMOULIS, MARTINS, 2006, p.129).

Implementou-se, assim, no Brasil, o chamado "Estado do bem-estar social", no qual o Estado assume funções de modelação da vida social, transformando-se de mero prestador de serviços públicos em empresário, desbravando setores comerciais e industriais, renovando estruturas sociais e econômicas (JUSTEN FILHO, p.2002) e se fazendo presente em áreas como o lazer, moradia, dentre outros que se afastam do clássico Estado Liberal.

Por positivar diversas melhorias à qualidade de vida da população, o welfare state proposto pela $\mathrm{CF} / 88$ alcançou, inicialmente, os resultados esperados: houve uma melhora gradativa nas condições de vida da sociedade brasileira e conferiu à Carta Constitucional a legitimidade necessária para se estabilizar socialmente e legitimar um novo regime, pondo por terra o perigo de uma volta de um governo ditatorial.

Este êxito trouxe consigo as causas de sua inviabilização. Ao passo que eram concedidos mais e mais direitos e vantagens à população, era necessária uma maior atuação do Estado e, consequentemente, um maior investimento deste. Sendo os recursos limitados, o montante de recursos vai se tornando insuficiente e a crise parece inevitável ao Estado. Apenas para exemplificar, a crise financeira vivida pelo Estado brasileiro, especialmente até 1999, com a moratória argentina, seguida da moratória do Estado de Minas Gerais tendo como causa (embora não unicamente) o fenômeno acima descrito. Entrando o BEZERRA JÚNIOR, J. A. Entre a Arbitragem Brasileira e a Arbitragem Europeia: Um estudo acerca da Agência Nacional de Telecomunicacões (ANATEL) e a Office of Comunications (OFCOM). Revista de Direito, Estado e Telecomunicações, Brasília, v. 9, n. 1, p. 69-92, maio de 2017. 
Estado em crise e não mais podendo assegurar (ou ampliar) as melhorias na qualidade de vida da população, ou mesmo dos serviços mais essenciais, a atuação estatal passa a perder legitimidade e a manutenção de sua base começa a ficar ameaçada (JUSTEN FILHO, 2002, p.19). O welfare state proposto pela $\mathrm{CF} / 88$ traz consigo as causas de sua própria derrocada.

Ao passo que houve uma profunda reforma na estrutura do Estado brasileiro, não ocorreram alterações constitucionais, de modo que temos novas estruturas, com legislação infraconstitucional adequada ao novo cenário sócioeconômico e um choque com uma Constituição ainda sob um modelo antigo, não totalmente compatível com a realidade atual.

O Estado Regulador se caracteriza por uma redução do Estado, em comparação com o welfare state, havendo uma concepção de subsidiariedade na atuação estatal, e, por outro lado, intervindo enfaticamente no mercado por intermédio de instrumentos verticais e horizontais. Embora o "Estado Regulador" seja conceito polissêmico, não admitindo apenas uma definição por isso a impossibilidade de importarmos automaticamente "modelos" prontos - é fato que a Constituição Federal de 1988, tal qual se nos apresenta atualmente, após 92 (noventa e duas) emendas a seu texto, ainda não perdeu suas características de promoção do bem estar social, sendo híbrida, oscilando entre um Estado Regulador e um Estado do welfare state, possuindo, contudo, mais características deste último. Ainda que contenha elementos variados, não podemos perder de vista que tais nomenclaturas são, como afirmado anteriormente, mais frutos de ideologias do que de posições propriamente jurídicas.

Assim, devemos analisar o Estado não sob a forma de um "Estado Regulador", "Estado do Bem Estar Social" ou mesmo um "Estado neoliberal". Perfilhando ensinamentos de Alexandre Aragão, acreditamos que "a denominação mais adequada para uma manifestação jus-política tão complexa e dinâmica é a de "Estado Democrático de Direito", denotadora da possibilidade do surgimento de diversos outros submodelos que detalhem o seu conteúdo (ARAGÃO, 2009, p.55).

O certo é que o conceito de regulação é um pressuposto do Estado Regulador, que se apoia no Estado garante dos direitos fundamentais, inclusive a igualdade de condições competitivas; no Estado de intervenção permanente e simbiótica; no Estado Administrativo, por sua apresentação de agigantamento da função de planejamento e gerenciamento das leis; no Estado legitimado na figura do administrador, do processo de gerenciamento normativo da realidade ou do espaço público regulador; no Estado de direitos dependentes de sua conformação objetiva em ambientes regulados; no Estado Subsidiário, em sua apresentação de potencialização da iniciativa privada via funções de fomento, coordenação e fiscalização de setores relevantes; e no conceito de regulação BEZERRA JÚNIOR, J. A. Entre a Arbitragem Brasileira e a Arbitragem Europeia: Um estudo acerca da Agência Nacional de Telecomunicaçoes (ANATEL) e a Office of Comunications (OFCOM). Revista de Direito, Estado e Telecomunicações, Brasília, v. 9, n. 1, p. 69-92, maio de 2017. 
como processo de realimentação contínua da decisão pelos efeitos da decisão, reconformando a atitude do regulador em uma cadeia infinita caracterizada pelo planejamento e gerenciamento conjuntural da realidade (ARANHA, 2015, p.32$33)$.

Alguns traços são comuns às agências reguladoras, tais como a independência dos dirigentes frente ao poder político, sua setorização bem como a natureza jurídica de autarquia em regime especial. Incluímos aqui o poder normativo e o poder de dirimir conflitos, visto que sintetiza estes dois que são limitados aos setores que visam regular.

A independência, por evidente, não quer dizer que estas estão livre de controle ou de fiscalização. Visando a implantar políticas públicas propostas democraticamente pelo Poder Legislativo, as agências devem manter-se independentes frente a este e ao próprio Poder Executivo, para que possa implementá-las da forma mais eficiente possível. Assim, esta independência visa, na visão de Alexandre Santos de Aragão, a compensar alguns dos inconvenientes do princípio majoritário, corrigindo eventuais distorções para as parcelas da população que não estiverem de acordo com as posturas adotadas pela maioria (ARAGÃO, 2009, p.88).

Esta independência tem diversas facetas, quais sejam: a) independência dos dirigentes frente ao Poder Executivo, por intermédio de mandatos por tempo determinado, não coincidentes com os mandatos do Poder Executivo, sendo vedada a livre exoneração; b) independência econômica e administrativa, tendo as agências suas próprias receitas provenientes, geralmente, do próprio setor regulado, bem como liberdade para contratar seu pessoal, sob o regime estatutário e celetista (dependendo do cargo); c) independência processual, sendo inadmitido o recurso hierárquico impróprio.

Esta independência não pode ser tomada literalmente e entendida como se estas pudessem inovar primariamente a ordem jurídica. $\mathrm{O}$ poder normativo destas é inegável; contudo, apenas poderão exercê-lo visando a complementar as normas-quadro (ou Standards) impostos pelo Poder Legislativo. O princípio da legalidade deve ser entendido de maneira ampla - princípio da juridicidade, escrevem alguns (MORAES, 2004) de maneira que os atos da agência são compreendidos exercendo função administrativa, devendo respeitar não apenas à Constituição, mas a lei que autorizou a expedição destes atos. Ademais, a supremacia destes entes não é uma supremacia geral, tal qual a do Estado frente a seus administrados, mas uma supremacia especial, onde uma característica (ou um conjunto de características) reúne um grupo de pessoas sob uma mesma condição, demandando tratamento diferenciado de quem não detém tais características (FIGUEIREDO, 2005, p.285).

A setorização a que nos referimos resume a função judicante, normativa e administrativa que possuem as agências reguladoras para dirigir o respectivo BEZERRA JÚNIOR, J. A. Entre a Arbitragem Brasileira e a Arbitragem Europeia: Um estudo acerca da Agência Nacional de Telecomunicaçoes (ANATEL) e a Office of Comunications (OFCOM). Revista de Direito, Estado e Telecomunicações, Brasília, v. 9, n. 1, p. 69-92, maio de 2017. 
setor. Devemos ressaltar que a tais poderes não se encontram livres de amarras, recebendo controle - embora um controle diferenciado do usual - quer do Poder Legislativo, Executivo e, principalmente, do Poder Judiciário, face ao princípio da inafastabilidade da jurisdição. Gustavo Binenbojm explica referido fenômeno afirmando que a clássica estrutural piramidal hierarquizada da Administração Pública está ruindo, dando lugar ao que ele denomina "Estado policêntrico", orientado pelo princípio da eficiência (BINENBOJM, 2006). A legitimidade de tais agências, para o autor, dar-se-ia não somente pela necessidade da eficiência na condução de alguns setores estratégicos, bem como no controle social exercido sobre tais agências e pelo procedimento.

As agências reguladoras exercem atividades de supremacia estatal, como práticas típicas de polícia, razão pela qual devem ingressar no ordenamento jurídico pátrio como sujeito de direito público, constantes da Administração indireta. Por demandarem uma certa autonomia, as agências reguladoras assumem status de autarquia que, conceitualmente, significam autogoverno, no sentido de pessoa jurídica administrativa com capacidade para gerir interesses próprios (CARVALHO FILHO, 2009, p.444). Não basta, todavia, a independência comum a toda autarquia, demandando as agências um grau mais intensificado de autonomia, como impossibilidade de demissão ad nutum dos dirigentes (com mandatos em tempo distinto dos mandatos dos chefes do Executivo), inexistência de recursos administrativo impróprio, dentre outras características. Assim, se fala que as agências reguladoras possuem, no direito brasileiro, natureza jurídica de autarquia em regime especial.

Embora a expressão "autarquia especial" ou "autarquia em regime especial" seja multifacetária, por comportar diversas possibilidades (a independência conferida pode ser maior ou menor, conforme a lei criadora da agência), faz-se mister ressaltar que apenas mediante a análise do instrumento legal específico de criação da agência, podemos verificar com maior precisão o grau de independência de determinada agência.

\section{A Arbitragem e a Agência Nacional de Telecomunicações (ANATEL)}

Recentemente, os métodos de administração da justiça brasileira vêm sendo alvo de diversas críticas, que se fundamentam, sobretudo, em sua morosidade e na complexidade do sistema. Seu custo, bem como sua facilidade para o ingresso, torna seu acesso indistinto a todos, o que não necessariamente significa uma adequada prestação jurisdicional, muito menos a concretização satisfatória dos valores constitucionais.

Diante do esgotamento e da morosidade do Poder Judiciário, cumpre encontrar alternativas à jurisdição estatal para a composição de controvérsias no âmbito das telecomunicações que sejam capazes de, diminuindo a litigiosidade e Nacional de Telecomunicações (ANATEL) e a Office of Comunications (OFCOM). Revista de Direito, Estado e Telecomunicações, Brasília, v. 9, n. 1, p. 69-92, maio de 2017. 
aumentado a legitimidade do resultado, oferecer respostas de forma mais rápida, técnica e eficaz, acompanhando os avanços da tecnologia que permeiam o setor. E a arbitragem se propõe à consecução de tais objetivos (SANTIAGO, 2014, p.177).

O uso da arbitragem em disputas envolvendo o Estado ainda encontra dificuldades fundadas no princípio da indisponibilidade do interesse público. A aplicação deste meio extrajudicial de resolução de disputas entre agência reguladora e concessionário e entre concessionários e usuários seria impossível, dado a natureza administrativa destas relações e o interesse público nelas envolvidos.

Dessa forma, a liberalização de mercados para a prestação de serviços de telecomunicações em âmbito mundial a partir da última década do século XX demandou a criação de órgãos reguladores do setor que buscassem resguardar o interesse público em meio a atuação dos entes privados. O Brasil procedeu à criação da Agência Nacional de Telecomunicações (ANATEL), que é um órgão autônomo cujo dever é regulamentar e fiscalizar o setor fundando-se em dois princípios de atuação: a universalização dos serviços básicos de telecomunicações e a ampla e justa concorrência na exploração de serviços (OLIVEIRA, 2009, p.112).

Entre os encargos oriundos do dever de garantir a competição, está o papel de resolver os conflitos entre operadoras. O papel do regulador é muito importante nesse sentido, principalmente quando se trata da necessidade de regulação concorrencial assimétrica, em que as operadoras já estabelecidas gozam de alto poder de mercado em virtude de possuírem a maior parte das redes de telecomunicações (OLIVEIRA, 2009, p.112).

Inicialmente, vale ressaltar que indisponível é o interesse público primário e não o interesse da administração (GRAU, 2016) Aquele é o resultado da união de complexos individuais em determinada sociedade ao passo que este é o interesse da estrutura organizacional da Administração Pública pautada pelo princípio da legalidade. Assim, uma vez que existe a possibilidade legal de qualquer pessoa capaz utilizar da arbitragem para dirimir litígios relativos a direitos patrimoniais disponíveis (art. $1^{\circ}$ Lei 9.307/96, e seus parágrafos incluídos pela Lei 13.120/2015), abre-se espaço normativo para a Administração Pública utilizar-se desse mecanismo em proveito de seus próprios interesses.

Ao optar pela arbitragem, a Administração Pública não negligencia um interesse público; ao revés, opta-se por um modo mais célere e especializado de solucionar conflitos técnicos que fogem ao padrão dos conflitos sujeitos ao Poder Judiciário e que, por isso mesmo, estarão mais sujeitos a proferir decisões que não agradem nenhuma das partes (PEREIRA; CAVALCANTE, 2010).

Um litígio envolvendo agentes do setor regulado ou um deles e a agência reguladora representa uma contradição, um período de crise, verdadeiro BEZERRA JÚNIOR, J. A. Entre a Arbitragem Brasileira e a Arbitragem Europeia: Um estudo acerca da Agência Nacional de Telecomunicacões (ANATEL) e a Office of Comunications (OFCOM). Revista de Direito, Estado e Telecomunicações, Brasília, v. 9, n. 1, p. 69-92, maio de 2017. 
disfuncionamento da ordem estabelecida. A possibilidade de utilização dos meios alternativos de resolução de disputas consubstancia a adoção de uma ferramenta de superação dessa crise, reforçando a coerência do sistema. A atuação estatal no sentido de possibilitar os meios alternativos de resolução de controvérsias, entre eles a arbitragem, traduz-se em uma atuação regulatória do Estado. Esse raciocínio se aplica à ANATEL e ao campo das telecomunicações (SANTIAGO, 2014, p.179).

O uso da arbitragem em setores econômicos regulados deverá vir expresso nos contratos firmados entre o Poder concedente e as empresas concessionárias, em cláusula compromissória. Portanto, salvo em casos de proibição expressa pela utilização deste meio, ou em casos de bens de uso comum do povo e de uso especial, quaisquer outras causas envolvendo direitos patrimoniais são arbitráveis (BINENBOJN, 2015).

Um dos pontos cruciais da arbitragem é o fato de ter como consequência a solução de litígios com maior celeridade, em um tempo menor se comparado ao processo judicial, marcado pela morosidade e pela possibilidade de se protelar o cumprimento da sentença. Esse ponto é importante, pois grandes operadoras de telecomunicações podem utilizar sua força econômica para impedir ao máximo a concretização de uma determinação judicial, ou até mesmo o sucesso de um acordo de que depende a operadora de menor porte para a prestação de seus serviços, violando a livre concorrência no setor.

A grande, talvez, celeuma por parte das telecomunicações é a maneira de se lidar com a controvérsia, notadamente em virtude da projeção de seus efeitos sobre a competição entre as operadoras e sobre a prestação de serviços. Qualquer atuação regulatória no setor deve, além de identificar esse desafio, priorizar novas formas de combatê-lo, o que passa pelo reconhecimento de que o Poder Judiciário não pode ser o único ator na composição desses conflitos.

Destarte, cumpre analisar o pano de fundo para a utilização dos meios extrajudiciais de solução de controvérsias na esfera das telecomunicações, de modo a verificar que alguns aspectos da regulação, o regime jurídico e as características do setor encontram plena harmonia com a composição extrajudicial de litígios e, consequentemente, com a arbitragem (SANTIAGO, 2014, p.183).

Um interesse social capaz de ser contemplado pela utilização da arbitragem nos litígios de telecomunicações diz respeito à maior probabilidade de justiça nas decisões arbitrais, visto que são prolatadas por pessoas especialistas nas matérias levadas ao seu convencimento. Além de haver a possibilidade de os árbitros serem auxiliados por peritos técnicos, o fato de eles serem especialistas em telecomunicações é capaz de propiciar uma decisão mais adequada aos agentes e usuários dos serviços, conferindo maior segurança jurídica e confiança à sociedade e às operadoras, o que solidifica a política BEZERRA JÚNIOR, J. A. Entre a Arbitragem Brasileira e a Arbitragem Europeia: Um estudo acerca da Agência Nacional de Telecomunicaçoes (ANATEL) e a Office of Comunications (OFCOM). Revista de Direito, Estado e Telecomunicações, Brasília, v. 9, n. 1, p. 69-92, maio de 2017. 
regulatória e acaba por trazer maiores possibilidades de ampliação do investimento privado (SANTIAGO, 2014, p.173).

É cediço que as empresas deduzem os custos da imprevisibilidade, da morosidade e da ineficácia do Poder Judiciário em seus investimentos, de modo que a arbitragem pode ser uma das ferramentas utilizadas pela ANATEL para combater esse cenário. Ademais, o interesse social mais evidente se refere ao aumento da participação dos agentes nos processos de decisão (SANTIAGO, 2014, p.187).

A introdução do modelo de agências reguladoras na Administração Pública brasileira teria resultado da identificação de um déficit de regulamentação traduzido nos seguintes aspectos, cuja concretização persegue: política tarifária definida e estável; marcos regulatórios mais claros, que detalhem as relações entre os diversos atores de cada setor, seus direitos e obrigações; mecanismo ágil e eficiente para a solução de divergências e conflitos entre o poder concedente e a concessionária; garantias contra os riscos econômicos e políticos dos investimentos em setores econômicos (ARANHA, 2005, p.57).

Não existe, no Brasil, um procedimento único de resolução de disputas entre agências reguladoras que abarque todos os tipos de conflito. As características principais desse processo são: a impossibilidade de as partes escolherem os "árbitros", na medida em que o artigo 10 da Resolução Conjunta no 2/2001 estabelece que a Comissão é composta por dois representantes de cada agência (ANEEL, ANATEL e ANP); (natureza jurídica de um procedimento administrativo, assim expressamente definido no artigo 19 da aludida Resolução; da decisão da Comissão não cabe recurso apenas na esfera administrativa (art. 36 da Resolução no 2/2001), sendo, por conseguinte, possível a revisão judicial do mérito; e possibilidade de apenas uma das partes solicitar a atuação das agências (Resolução no 1/1999, art. 14, §2).

No que se refere o conflito ser solucionado por meio da intervenção de um terceiro, em procedimento cujo início é facultativo, não há, em geral, a escolha por ambas as partes, e nem uma convenção prévia que afasta a jurisdição estatal, impossibilitando o recurso revisional de mérito ao Poder Judiciário.

Somado a tudo isso, inexiste a fundamental presença crucial do princípio da autonomia da vontade, seja na escolha do arbitro ou das regras procedimentais, para se concluir pela existência da arbitragem. Pelo contrário, as aludidas hipóteses se aproximam mais a uma espécie de manifestação de arbitramento administrativo por parte da ANATEL, como forma de exemplo.

O que acontece em boa parte é o caminho para uma negociação prévia acerca da interconexão de redes ou do compartilhamento de infraestrutura e as partes não conseguem chegar a um consenso em virtude da falta de algum BEZERRA JÚNIOR, J. A. Entre a Arbitragem Brasileira e a Arbitragem Europeia: Um estudo acerca da Agência Nacional de Telecomunicaçoes (ANATEL) e a Office of Comunications (OFCOM). Revista de Direito, Estado e Telecomunicações, Brasília, v. 9, n. 1, p. 69-92, maio de 2017. 
elemento para a formação do negócio jurídico. A agência, então, é chamada por uma ou ambas as partes para, exercendo seu poder, integrar o conteúdo dessa negociação que, anteriormente, não obteve sucesso.

Vislumbra-se que a opção pela cláusula compromissória em setores econômicos reguláveis dependerá do desenho regulatório do setor, e poderá prever a arbitragem entre o Poder público e o concessionário, entre os agentes econômicos ou entre estes e seus consumidores, não interferindo com as competências das agências reguladoras setoriais (ARANHA, 2005, p.234). As agências reguladoras mantêm a mediação de conflitos entre agentes bem como seu poder de aplicar sanções às empresas, consistindo a arbitragem apenas em um outro meio extrajudicial de serem atingidos os fins regulatórios.

A cláusula compromissória pactuada pelas partes, assinalada por lei a algumas agências reguladoras que confere poder de arbitramento aos entes reguladores implica que as soluções deverão ser solucionadas por arbitragem em câmara arbitral. Embora o nomen juris utilizado por alguns dispositivos legais ("arbitramento") possa levar ao entendimento de que as agências reguladoras poderão diretamente arbitrar os conflitos dos agentes econômicos a elas submetidos, compete, em verdade, às agências somente proferir decisões administrativas, não gozando dos efeitos jurídicos que dispõe a decisão arbitral, conforme a Lei 9.307/96. Ademais, quando as partes convencionam a cláusula arbitral, estão renunciando qualquer outra instancia decisória, seja administrativa ou judicial (BINENBOJN, 2015, p.235).

As decisões emanadas no seio das agências reguladoras são, portanto, decisões administrativas acerca das questões que lhes sejam submetidas, não gozando de executividade e podendo ser judicializadas. As decisões provenientes de tribunais arbitrais, por seu turno, produzem os mesmos efeitos de sentença proferida pelo Poder Judiciário, consistindo em título executivo, sendo mais céleres e dotadas de maior legitimidade, em regra, dada a especialização dos árbitros e a confiança que estes gozam das partes.

O procedimento instituído pelo Regulamento Geral de Interconexão em muito carece de mecanismos-chave do procedimento de arbitragem, tal como construído tradicionalmente, bem como destoa das disposições da Lei $n$. 9.307/1996, que regula a arbitragem no Brasil. Nessa esteira, pode-se sustentar que, em verdade, esse procedimento não se trata de arbitragem, mas de um processo administrativo de resolução de disputas em interconexão.

Surgindo algum conflito que envolva operadoras de telecomunicações, concernente a compartilhamento de infraestrutura, o procedimento a ser seguido depende das partes que estiverem em conflito. Se uma delas for operadora de telecomunicações e a outra se submeter à disciplina regulatória da ANP ou da ANEEL, a competência passa, por força das resoluções conjuntas ANEELANATEL-ANP n. 1/1999 e n. 2/2001, para a Comissão de Resolução de BEZERRA JÚNIOR, J. A. Entre a Arbitragem Brasileira e a Arbitragem Europeia: Um estudo acerca da Agência Nacional de Telecomunicaçoes (ANATEL) e a Office of Comunications (OFCOM). Revista de Direito, Estado 
Conflitos das Agências Reguladoras dos Setores de Energia Elétrica, Telecomunicações e Petróleo (REZIO, 2002).

As disputas surgidas entre operadoras de telecomunicações não se submetem ao Regulamento Conjunto anteriormente mencionado, mas às formas compositivas previstas no próprio regulamento de compartilhamento de infraestrutura, aprovado pela Resolução n. 274. Essas formas são a arbitragem e a mediação administrativas.

Para se usarem esses meios de resolução de disputas, a negociação entre as partes deve ter sido infrutífera. O Regulamento remete aos procedimentos de arbitragem e de mediação aprovados pela Agência. No entanto, não há procedimentos gerais para qualquer dessas RDs no âmbito da ANATEL: não existe procedimento de mediação aprovado pela Agência e o procedimento de "arbitragem" existente refere-se à "arbitragem em interconexão", sobre a qual já se discorreu.

Além desses meios de resolução de disputa, também se menciona a arbitragem e a mediação de conflitos entre operadoras pela ANATEL em seu Regimento Interno e nos contratos de concessão, carecendo da mesma regulamentação. Pelos contratos de concessão, as partes têm a faculdade de submeter à ANATEL, por meio de reunião de composição de conflitos, de processo de mediação ou de processo de arbitragem, quaisquer conflitos decorrentes da interpretação e da aplicação da regulamentação.

Conforme se demonstrou com o mapeamento feito na subseção anterior, não há um procedimento de arbitragem e um procedimento de mediação regulamentados na ANATEL que sejam amplamente aplicáveis. Assim, tratarse-á, aqui, de utilização do direito comparado para iluminar a concepção de mediação e de arbitragem que a Agência brasileira carrega e, a partir disso, indicar caminhos possíveis e coerentes com a posição de um órgão regulador frente a um mercado liberalizado (OLIVEIRA, 2009, p. 143).

\section{A Arbitragem e a Office of Communications (OFCOM)}

Ao se observar a resolução de conflitos na Comunidade Europeia, percebe-se uma realidade favorável, qual seja, em inúmeros litígios que ocorrem na Europa, é comum a utilização da arbitragem do que o próprio Poder Judiciário. Isso ocorre porque as grandes disputas europeias, não apenas no setor de telecomunicações, mas no de energia elétrica, de transportes e nos setores comerciais em geral, frequentemente envolvem mais de um país, visto que a maioria das grandes empresas é transnacional.

Vislumbra-se um grande apreço aos métodos de resolução de disputas, na medida em que eles propiciam uma neutralidade de foro. Não se confere a decisão ao Poder Judiciário ou ao órgão regulador de um país específico, mas Nacional de Telecomunicações (ANATEL) e a Office of Comunications (OFCOM). Revista de Direito, Estado e Telecomunicações, Brasília, v. 9, n. 1, p. 69-92, maio de 2017. 
escolhem-se árbitros a partir do comum acordo das partes ou, ainda, apontam-se instituições de âmbito internacional que prestam o serviço de arbitragem em disputas comerciais. Isso é importante principalmente quando a disputa concerne a duas ou mais empresas com sede em diferentes países. Na resolução de disputas em telecomunicações pelas autoridades reguladoras, essa tradição não é desprezada.

$\mathrm{Na}$ Europa, há normas de âmbito continental promulgadas pelos respectivos DGs da União Europeia (Europe Union Framework Directives). O setor de redes e serviços de comunicação eletrônica é regido pela Diretiva 2002/21/EC, de 7 de março de 2002. Essa norma aborda, em seus artigos 20 e 21, a posição dos órgãos reguladores na resolução de disputas entre operadoras de telecomunicações em países regidos pela Diretiva (OLIVEIRA, 2009, p. 144).

Segundo esse instrumento normativo, a autoridade regulatória nacional deve decidir de forma vinculativa para as partes, no prazo máximo de quatro meses, quando uma delas requer solução a uma disputa referente a qualquer norma ou diretiva do setor - inclusive a própria Diretiva 2002/21/EC. No entanto, é dever dos Estados-Membros garantirem a capacidade de as autoridades regulatórias declinarem de resolver a disputa quando outros mecanismos - inclusive a mediação - existirem e contribuírem de maneira mais efetiva para a resolução da disputa em um prazo aceitável. Assim, sendo cabíveis a arbitragem ou a mediação no caso, a autoridade regulatória informa às partes que não solucionará a disputa. Se esses mecanismos de resolução de disputa não trouxerem resultado em quatro meses, a autoridade regulatória deve se comprometer a decidir a questão (OLIVEIRA, 2009, p. 145).

Na possibilidade de uma disputa surgir entre duas empresas domiciliadas em países distintos, pode-se requerer a decisão a qualquer das autoridades regulatórias nacionais envolvidas. Elas, entretanto, trabalharão em conjunto para se alcançar uma decisão ao caso. Nesse tipo de conflito, também se aplica a possibilidade de as autoridades regulatórias declinarem, se existirem outros métodos de resolução de disputa. Sendo este o caso, só decidirão depois de não se ter alcançado resultado com esses métodos após quatro meses (OLIVEIRA, 2009, p. 145).

As decisões dos órgãos reguladores são públicas, aliás, características comuns aos meios consensuais de solução de conflitos, respeitando-se, todavia, os requerimentos das partes pela confidencialidade de aspectos negociais das empresas. Essa decisão não faz o acesso das partes ao Poder Judiciário precluir, podendo elas ir à busca de uma revisão judicial do mérito já analisado.

Nas suas decisões, as autoridades regulatórias nacionais devem observar alguns princípios. São esses: garantir que os usuários beneficiem-se ao máximo em relação ao poder de escolha, ao preço e à qualidade, garantir que não haja BEZERRA JÚNIOR, J. A. Entre a Arbitragem Brasileira e a Arbitragem Europeia: Um estudo acerca da Agência Nacional de Telecomunicacooes (ANATEL) e a Office of Comunications (OFCOM). Revista de Direito, Estado e Telecomunicações, Brasília, v. 9, n. 1, p. 69-92, maio de 2017. 
distorções ou restrições no mercado, encorajar investimentos em infraestrutura e promover inovações, ensejar o uso eficiente de radiofrequências e de recursos de numeração, remover barreiras compartilhamento de infraestrutura e à prestação de serviços, encorajar a existência de redes, serviços e conectividade transnacionais, garantir que todos os usuários tenham acesso a um serviço universal, proteger os consumidores nas negociações com as operadoras, criando inclusive mecanismos próprios de resolução de disputas consumidor-operadora, ensejar a proteção de dados pessoais e da privacidade, promover a transparência das tarifas e das condições de uso de serviços de telecomunicações de interesse coletivo, suprir as demandas das minorias por acessibilidade e garantir a integridade e a segurança das redes públicas de telecomunicação (OLIVEIRA, 2009, p. 146).

Diante dessa diretiva europeia, o Reino Unido promulgou o Communications Act de 2003, criando o Office of Communications (Ofcom), órgão regulador do setor de telecomunicações, que trouxe novas atribuições à atividade regulatória. Entre tais atribuições, está a competência de resolver disputas entre operadoras de telecomunicações. O Communications Act é um documento extenso e trata pormenorizadamente desse papel do Ofcom.

Primeiramente, para que se tenha a resolução de uma disputa pelo Ofcom, basta que uma das partes a solicite. Na linha da diretiva da União Europeia, a disputa só será resolvida pelo órgão regulador se não houver meios alternativos para resolver a disputa, caso esses meios alternativos sejam cabíveis ao tipo de disputa. Seja qual for o posicionamento do órgão, as partes são notificadas. No caso de o Ofcom declinar e, depois de iniciado o procedimento alternativo de resolução de disputa, não se alcançar uma conclusão em quatro meses, uma das partes tem o direito de solicitar que o órgão resolva a disputa e este é obrigado a fazê-lo. Neste caso, o processo anterior será continuado (OLIVEIRA, 2009, p. 146).

No procedimento de resolução de disputa, o Ofcom tem o poder de: declarar os direitos e as obrigações das partes em disputa; firmar uma direção para as partes, fixando os termos e as condições das transações entre elas e obrigando-as a entrar em processo de negociação com base nessas condições; determinar que uma das partes cumpra o pagamento para com a outra; e/ou modificar ou revogar condições gerais, de universalização, condições de acessibilidade. O órgão regulador tem o poder de requerer das partes todas as informações necessárias e resolver se é apropriado que o Ofcom decida no caso ou se deve consultar outros estados-membros, e ainda pode exigir todas as informações que sejam importantes para a análise da disputa e para a decisão. $\mathrm{O}$ órgão tem o poder de realizar essas solicitações não só às partes, mas a terceiros que possuam informações relevantes nesse sentido.

Percebe-se que não há cobrança de pagamento por essa prestação de BEZERRA JÚNIOR, J. A. Entre a Arbitragem Brasileira e a Arbitragem Europeia: Um estudo acerca da Agência Nacional de Telecomunicacões (ANATEL) e a Office of Comunications (OFCOM). Revista de Direito, Estado e Telecomunicações, Brasília, v. 9, n. 1, p. 69-92, maio de 2017. 
serviço do $O f c o m$, a não ser que a parte que solicitou a decisão do órgão o tenha feito em condições abusivas, vexatórias ou frívolas. A decisão deve ser entregue pelo órgão em até quatro meses. Uma cópia da decisão, com seus fundamentos, é enviada para cada uma das partes. Os trechos da decisão que o órgão considerar apropriados para ir a público serão publicados.

No que se refere a questão recursal, da decisão do Ofcom cabe apelação apenas para o Tribunal, em procedimento judicial próprio. Deve-se notificar o órgão regulador da apelação citando a decisão apelada e os fundamentos da apelação. Tais fundamentos devem permitir identificar se o que levou a parte a apelar foi um erro de fato ou de direito, ou ambos, e se a parte apela do exercício da discricionariedade pelo Ofcom.

Ao lidar com a apelação, o Tribunal deve, de acordo com normas editadas por ele próprio, remeter as questões que envolvem controle de preço à entidade reguladora da concorrência. A decisão do Tribunal também pode, por sua vez, ser recorrida, mas tal recurso passa por um juízo de admissibilidade e deve se restringir a questões de legalidade e não de fatos. Portanto, como se vê, o Ofcom, nos procedimentos de resolução de disputas, atua, de uma forma bastante singular, no papel análogo ao de uma primeira instância judiciária (OLIVEIRA, 2009, p. 147).

Observa-se, por fim, um maior grau de evolução, no continente europeu, um grande envolvimento com relação aos métodos de resolução de disputas. Não apenas pela neutralidade de foro, mas também pelo fato de não se conferir determinadas decisões ao Poder Judiciário ou ao órgão regulador de um país específico, mas sim aos árbitros, a partir do comum acordo das partes, sempre apontando instituições de âmbito internacional que prestam o serviço de arbitragem em disputas comerciais. Isso é importante, se comparado ao Brasil, pois demonstra que na resolução de disputas em telecomunicações pelas autoridades reguladoras, essa tradição não é desprezada.

\section{Conclusões}

Recentemente, os métodos de administração da justiça brasileira vêm sendo alvo de diversas críticas, que se fundamentam, sobretudo, em sua morosidade e na complexidade do sistema. Seu custo, bem como sua facilidade para o ingresso, torna seu acesso indistinto a todos, o que não necessariamente significa uma adequada prestação jurisdicional, muito menos a concretização satisfatória dos valores constitucionais.

O presente texto visou a discorrer sobre a utilização da arbitragem como técnica de resolução de litígios em setores econômicos regulados, ao lado das decisões emanadas pelas agências reguladoras e de decisões judiciais. As agências reguladoras no Brasil, em especial após o fenômeno da desestatização, Nacional de Telecomunicacooes (ANATEL) e a Office of Comunications (OFCOM). Revista de Direito, Estado 
gozam de crescente importância, servindo como um órgão de proteção do consumidor, de efetivação de políticas públicas setoriais e de fiscalização e indução do ambiente econômico regulado. Com isso, suas competências multiplicam-se à medida que cresce o setor regulado.

Uma das principais atribuições das agências reguladoras é arbitrar conflitos oriundos entre Poder Público e empresas concessionárias e entre estas entre si bem como entre concessionárias e consumidores, visando a proferir decisões mais céleres e especializadas, sobretudo em conflitos técnicos de grau elevado de complexidade que dificilmente seriam solucionadas a contento pelo Poder Judiciário. Tais decisões gozam ainda de maior legitimidade, uma vez que proferidas no interior do ordenamento jurídico setorial, em um ambiente seguro e conhecido pelas partes.

A utilização da arbitragem pelo Poder público, tal qual prevista pela Lei 9.307/96 foi alvo de severas objeções, fundamentando-se especialmente na indisponibilidade do interesse público. Isto porque os dois institutos arbitragem no âmbito das agências reguladoras e ex vi da Lei 9.307/96 conquanto terem a mesma nomenclatura jurídica, são essencialmente distintas; enquanto aquela trata-se de uma decisão administrativa, não gozando de executividade e sendo passível de ser judicializada, esta constitui título executivo e tem os mesmos efeitos da sentença proferida pelo Poder Judiciário.

O interesse público indisponível é aquele interesse primário, não se distinguindo do interesse público secundário, ou interesse da Administração. É inconteste a vontade do Poder Público de ver seus conflitos serem solucionados rapidamente e de maneira especializada, com uma maior probabilidade de uma decisão justa e legítima, face a um processo longo, demorado e dispendioso do Poder Judiciário e com uma maior probabilidade de findar com uma decisão que não atenda às partes.

Nesse sentido, a Lei 13.129 de 26 de maio de 2015 tenta resolver este entrevero, afirmando textualmente que a Administração Pública poderá utilizarse da arbitragem para dirimir conflitos relativos a direitos patrimoniais disponíveis.

Pode-se observar que, no âmbito das agências reguladoras, vislumbramse duas arbitragens, quais sejam, aquela emanada pela própria agência, que constitui decisão administrativa bem como aquela submetida a tribunal ou câmara arbitral, nos moldes da Lei 9.307/96, cuja decisão terá os mesmos efeitos daquela emanada pelo Poder Judiciário e, se condenatória, constituirá título executivo.

No que se refere a arbitragem europeia, a resolução de disputas pelo Ofcom, na Inglaterra, segue as diretrizes europeias não tratam analiticamente de todos os tipos de disputa que podem ser resolvidos administrativamente pelo órgão. Em vez disso, a regulação apenas informa principiologicamente que a BEZERRA JÚNIOR, J. A. Entre a Arbitragem Brasileira e a Arbitragem Europeia: Um estudo acerca da Agência Nacional de Telecomunicaçoes (ANATEL) e a Office of Comunications (OFCOM). Revista de Direito, Estado e Telecomunicações, Brasília, v. 9, n. 1, p. 69-92, maio de 2017. 
disputa deve ser referente à norma ou diretiva do setor.

Podemos observar pontos em comum com o Brasil, um vez que ele segue a técnica europeia para definição de que matérias podem ser dirimidas pela ANATEL. Assim, a arbitragem deve tratar de pendências relativas ao reconhecimento ou atribuição de direitos entre as partes, e a arbitragem, de “conflito de interesses entre operadoras de telecomunicações. É uma forma válida, pois não se corre o risco de determinado caso demandar a intervenção da agência e isso não poder ocorrer pela disputa não se enquadrar na listagem taxativa de hipóteses.

É possível observar pontos negativos também. O principal deles é a possibilidade de desvio de finalidade na atuação da agência. Uma disputa que não versa propriamente sobre a matéria que é objeto de regulação pela agência pode passar a ter de ser resolvida por ela. Se uma operadora de TV a cabo expõe indevidamente, em uma propaganda sua, a marca de uma operadora de SMP, tem-se, aí, um conflito de interesses, que, em tese, pode ser posto perante a agência. Dessa forma, muito dificilmente um conflito como esse prejudicará a concorrência entre as partes a ponto de a Agência precisar intervir.

Portanto, a melhor maneira de previsão da atuação da Agência parece mesmo ser a listagem analítica de hipóteses. É importante, no entanto, também deixar a agência decidir discricionariamente se deve atuar ou não em algum outro caso não contemplado pelo rol de hipóteses, mas que venha a ser potencialmente prejudicial a uma ampla e justa concorrência.

A arbitragem na ANATEL é sempre faculdade das partes, que, antes de solicitar a atuação da agência, têm de entrar em consenso sobre isso. A regulamentação do procedimento na Inglaterra (Europa) não traz essa necessidade.

No Regimento Interno da ANATEL, há a exigência de consenso tanto para a instauração da arbitragem pela Agência quanto para o início da mediação. Faz sentido, como se demonstrou, exigir o consenso das partes para que a Agência proceda à mediação. Já, na arbitragem, exigir o consenso das partes pode significar a necessidade inequívoca de a empresa solicitante ter de ir ao Judiciário, frustrando-se a possibilidade de uma decisão rápida e bem fundamentada ao conflito.

Esse problema foi identificado pelo chamado procedimento de arbitragem em interconexão da ANATEL, porém a arbitragem prevista no Regimento Interno, que rege tudo o mais, não se atentou para isso. Se o conflito tiver implicações concorrenciais perniciosas para a parte solicitante, a agência deveria, em nome do interesse público, ser capaz de ingressar e dirimir o conflito, como uma espécie de regulação assimétrica.

Observa-se pontos positivos da realização da arbitragem por uma instituição regulatória oficial são a possibilidade de se iniciar o processo sem BEZERRA JÚNIOR, J. A. Entre a Arbitragem Brasileira e a Arbitragem Europeia: Um estudo acerca da Agência Nacional de Telecomunicacooes (ANATEL) e a Office of Comunications (OFCOM). Revista de Direito, Estado e Telecomunicações, Brasília, v. 9, n. 1, p. 69-92, maio de 2017. 
uma concordância prévia da outra parte e a restrição dada à revisão da decisão pelo Poder Judiciário. Esses pontos colaboram para que a decisão definitiva da causa ocorra de maneira célere, contemplando, assim, o interesse público de proteção da concorrência entre as operadoras.

A formação de procedimentos de arbitragem e mais eficazes e fiéis é uma necessidade cuja satisfação depende de grande vontade política e - mormente no caso da mediação - de recursos humanos bem preparados para isso. Isso parece ter sido captado pela ANATEL, que talvez crie, em sua reforma estrutural, uma área especializada em composição de conflitos entre prestadoras de serviços de telecomunicações.

Ainda assim, a partir da leitura da atuação da agência brasileira, comparando-a com outros países, vê-se a necessidade de uma previsão em lei da realização da arbitragem. Caso contrário, a ANATEL deverá submeter-se à Lei de Arbitragem ordinária. Em suma, sem uma previsão legal específica para a prática da arbitragem pela Agência, os dois trunfos apontados linhas acima não podem efetivar-se.

Uma observação nos leva ao entendimento de que o procedimento de arbitragem privada comum tem pressupostos distintos da arbitragem conduzida por um órgão regulador, e, para que se façam efetivamente presentes esses pressupostos, precisa-se ter um procedimento diferenciado, porém ainda fiel aos aspectos essenciais de uma arbitragem. É verdade que essa necessidade de um procedimento próprio, especial, não ocorre tanto com a mediação praticada pelo órgão regulador.

Por outra via, o investimento público que se tem de fazer para se formar um bom mediador é maior que o investimento feito para se ter um bom árbitro. O resultado da mediação é, por outro lado, mais legítimo que o da arbitragem.

Concluindo, a arbitragem é forma complementar de resolução de disputas. Um órgão regulador de telecomunicações deve praticar com eficiência essas duas resoluções de disputas (RDs) perante um mercado liberalizado, de sorte a permitir que os conflitos entre as operadoras causem o menor dano possível à concorrência entre as empresas, o que se consegue por meio de uma resolução definitiva, rápida e legítima das disputas.

\section{Referências Bibliográficas}

ARAGÃO, Alexandre Santos. Agências Reguladoras e a Evolução do Direito Administrativo Econômico. 2 ed. Rio de Janeiro: Forense, 2009.

ARANHA, Márcio Iorio. Políticas públicas comparadas de telecomunicações (Brasila-EUA). Brasília, 2005. Tese de Doutorado. Centro de Pesquisa e Pós-graduação sobre as Américas. Universidade de Brasília. 
ARANHA, Márcio Iorio. Manual de Direito Regulatório. 3ed. Londres: Laccademia Publishing, 2015.

BINENBOJN, Gustavo. Arbitragem em Ambientes Regulados e sua relação com as competências das agências reguladoras. In MORAES, Carlos Eduardo Guerra, RIBEIRO, Ricardo Lodi. Direito Público Uerj. Vol 8. Rio de Janeiro. Freitas Batos, 2015.

CARMONA, Carlos Alberto. Arbitragem e Processo: Um comentário à Lei 9.307/96. 3ed. São Paulo: Atlas, 2009.

CARREAU, Dominique. BICHARA, Jahyr-Philippe. Direito Internacional. Rio de Janeiro, Lumen Juris, 2015.

CARVAlHO FILHO, José dos Santos. Manual de Direito Administrativo. 21 ed. Rio de Janeiro: Lúmen Júris, 2009.

DIMOULIS, Dimitri, MARTINS, Leonardo. Teoria Geral dos Direitos Fundamentais. São Paulo: Revista dos Tribunais, 2006.

DOLINGER, Jacob. Conciliação e Arbitragem no Direito Judaico, apud AYOUB, Luiz Roberto. Arbitragem: o acesso à justiça e a efetividade do processo - uma nova proposta. Rio de Janeiro: Lumen Juris, 2005.

FIGUEIREDO, Marcelo. As agências reguladoras: O Estado Democrático de Direito no Brasil e sua atividade normativa. São Paulo: Malheiros, 2005.

GRAU, Eros Roberto. Arbitragem e contrato administrativo. Disponível em:< http://www.epm.tjsp.jus.br/FileFetch.ashx?id_arquivo=20533> . Acesso em: 10 abr. 2016.

JUSTEN FILHO, Marçal. O Direito das Agências Reguladoras Independentes. São Paulo: Dialética, 2002.

MELlo, Celso D. de Albuquerque. Curso de Direito Internacional Público. Vol.II, 15ed. Rio de Janeiro: Renovar, 2004.

MORAES, Germana de Oliveira. Controle Jurisdicional da Administração Pública. 2 ed. São Paulo: Dialética, 2004.

OLIVEIRA, Artur Coimbra de. O papel do órgão regulador na resolução de disputas entre operadoras de telecomunicações: a arbitragem e a mediação à luz das experiências japonesa, inglesa e americana. Brasília: Revista de Direito, Estado e Telecomunicações, v. 1, n. 1, 2009. 
SANTIAGO, Rafael da Silva. Arbitragem e regulação: uma análise da aplicação do juízo arbitral no setor das telecomunicações. In Arbitragem e Regulação: Uma análise da aplicação do juízo arbitral. 2014.

SOUTO, Marcos Juruena Villela. Desestatização, Privatização, Concessões e Terceirizações. 3 ed. Rio de Janeiro: Forense, 2012.

REZIO, Juliana Oliveira. Resolução de Conflitos em Compartilhamento de Infra-Estrutura. In: Revista Teletime, Ano 5, n. 41, fevereiro de 2002. 
BEZERRA JÚNIOR, J. A. Entre a Arbitragem Brasileira e a Arbitragem Europeia: Um estudo acerca da Agência Nacional de Telecomunicaçoes (ANATEL) e a Office of Comunications (OFCOM). Revista de Direito, Estado e Telecomunicações, Brasília, v. 9, n. 1, p. 69-92, maio de 2017.

[DOI: https://doi.org/10.26512/lstr.v9i1.21514] 